\title{
Fusion Zone and HAZ Prediction Through 3-D Simulation of Welding Thermal Cycle
}

\author{
N.R. Mandal' ${ }^{1}$ and Malabika Adak ${ }^{2}$ \\ 'Associate Professor, ${ }^{2}$ Student \\ Department of Ocean Engineering and Naval Architecture \\ IIT, Kharagpur, Pin-721302, India
}

\begin{abstract}
An implicit centre difference scheme with a simplified heat source model has been implemented to simulate the transient 3-D thermal cycle. The parameters defining the heat source model, presented in this work, can easily be estimated unlike in the case of ellipsoidal or Gaussian heat source models. The transient temperature distribution was obtained with convection boundary conditions on all the three plate boundaries and top and bottom surfaces. The governing equations were represented in a finite difference form following centre difference implicit scheme. Jacobi iteration scheme with under- relaxation has been implemented to solve the system of difference equations. The temperature dependence of the thermo-physical properties have been incorporated by an iterative process subject to a predefined convergence criterion. The Jacobi iteration and iteration to accommodate variation of thermo-physical properties with temperature run simultaneously. The entire code has been written in $\mathrm{VC}++$ environment. The numerical results for the fusion zone dimensions compared fairly well with those of experiments. Increase in plate thickness indicated increase in cooling rate. For thicker plate, cooling rate stabilised faster as compared to thinner plate.
\end{abstract}

\section{INTRODUCTION}

An arc welding process consists of continuous heat input leading to fusion of parent and filler metal. The fusion of the parent metal forms the weld pool whereas that of filler metal leads to metal deposition and formation of top and bottom reinforcement. The weld parameters control the heat input, which in term control the weld geometry. The weld geometry can be represented by width of top reinforcement, bottom reinforcement and depth of joint penetration. A good weld is generally characterised by a relatively high depth to width ratio as well as minimum width of heat affected zone (HAZ). Therefore, the weld geometry and $\mathrm{HAZ}$ must be controlled to ensure uniform weld quality.

During welding, the interaction of the heat source and the parent metal leads to rapid heating and melting with vigorous circulation of molten metal in the weld pool. As the welding arc moves away from the molten region the cooling phase starts, leading to solidification and gradual cooling down to ambient temperature. 
The resulting thermal cycle plays an important role in determining weld geometry, HAZ dimensions, weld metal and HAZ microstructure, residual stress and deformation.

The aim of this investigation was to numerically simulate the welding process and to evaluate its physical characteristics. The critical first step towards achieving this goal is to accurately compute the transient temperature field.

Since the welding process involves very complex physical and metallurgical changes in the parent metal, it becomes practically impossible to establish an exact mathematical model of a welding process. The nonlinear and temperature-dependent physical parameters make the problem even more complex.

Because of the underlying importance of prediction of welding thermal history, it has led a number of researchers to investigate this problem /1-12/. Rosenthal /1, 2/ premiered this field of research. His analytical solution, based on the assumption of point and line heat source with temperature invariant physical properties, and without surface heat transfer, has been used worldwide to predict welding thermal history and cooling rates. Rosenthal solution provided fairly well predictions for points far away from the heat source, however for the regions closer to the heat source, it failed to give good predictions.

Since then various researchers have put forward various modifications incorporating more realistic assumptions such as distributed heat source, change of phase, circulation in weld pool, etc. Tsao et al. /3-6/ used simplified models ignoring the effect of fluid flow in the weld pool. Fluid flow in the weld pool can significantly affect the time-temperature history experienced by a weld metal $/ 13 /$. The role of Marangoni, electromagnetic and buoyancy forces on the weld pool geometry has been investigated $/ 7,8 \%$. Ohring and Lugt's /14/ model for investigating GMA weld pool included heat transfer, radiation, evaporation and viscous stress in the deformable free-surface boundary conditions. Ohring and Lugt incorporated all these aspects but at the same time made a gross assumption of constant material properties, whereas Mundra et al. $/ 13 /$ used specific heat and thermal conductivity values for solid and liquid metal only.

The purpose of the present study is to predict the fusion zone and HAZ dimensions through numerical simulation of the time dependent thermal cycle in submerged arc welding process considering temperature dependent material properties, latent heat of fusion under different cases of surface heat transfer.

\section{HEAT FLOW SIMULATION}

\section{Assumptions in Problem Formulation}

During consumable electrode welding the work piece receives energy both from the arc as well as from the metal droplets. The arc energy remains fairly constant, and does not change significantly with time, whereas the energy transfer from the metal droplets depends on various parameters like metal transfer mode, frequency of droplets, droplet size and its temperature. Now these phenomena are very much transient in nature and the resulting complexity makes it extremely difficult to incorporate them in a numerical scheme. Therefore, the total energy transfer from arc and metal droplets has been coupled together and expressed as an overall arc heat transfer efficiency. For various energy distribution, it has been reported that it results in a 
small variation of peak temperature and does not significantly affect the cooling rate in the $800-500^{\circ} \mathrm{C}$ range $/ 13 /$.

The mathematical modelling of arc heat, as taken by several investigators $/ 13,14,15$ / is primarily based on a Gaussian distribution of power density. The models assumed various geometries, from circular, spherical to double-ellipsoidal. The latter one has the advantage of easily changing the size and shape of the heat source to model both the shallow and deep penetration arc welding processes. However, the major constraint in using the most flexible and versatile double-ellipsoidal model is that it involves suitably choosing the four ellipsoidal parameters and two heat input fractions. The accuracy of thermal cycle prediction will depend on these six assumed parameters. Hence the sophistication does not necessarily improve the model's efficiency.

In the present investigation a much simplified model of uniform heat flux distribution over a rectangular parallelepiped /16/ has been taken. It has the major advantage of easy implementation in finite difference schemes as well as needing only 3 parameters to be suitably chosen, out of which length and width approximating the surface fusion boundary dimensions can be kept fixed for different plate thickness. Here for plates from 6 to $12 \mathrm{~mm}$ thickness, while considering single side single pass welding, the depth parameter of the heat source distribution is taken equal to $5 \mathrm{~mm}$, half width $3 \mathrm{~mm}$ and length $5 \mathrm{~mm}$.

\section{Temperature Dependent Material Properties}

The variation of specific heat and thermal conductivity with temperature /17/ have been incorporated in the calculation of thermal history. The temperature dependence of these parameters is shown in Figs. 1 and 2.

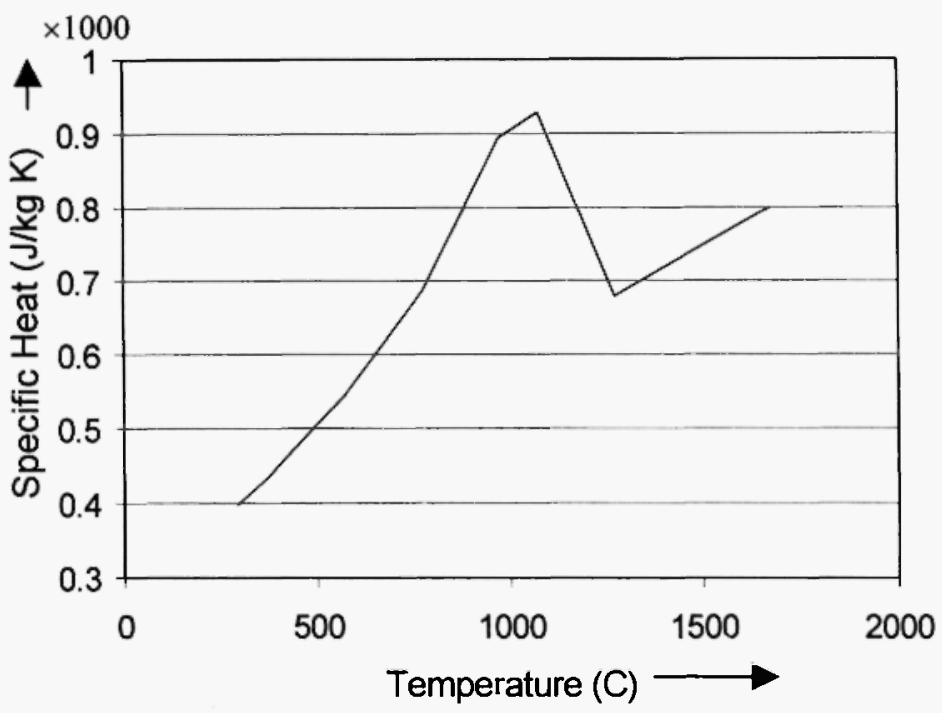

Fig. 1: Variation of specific heat with temperature 


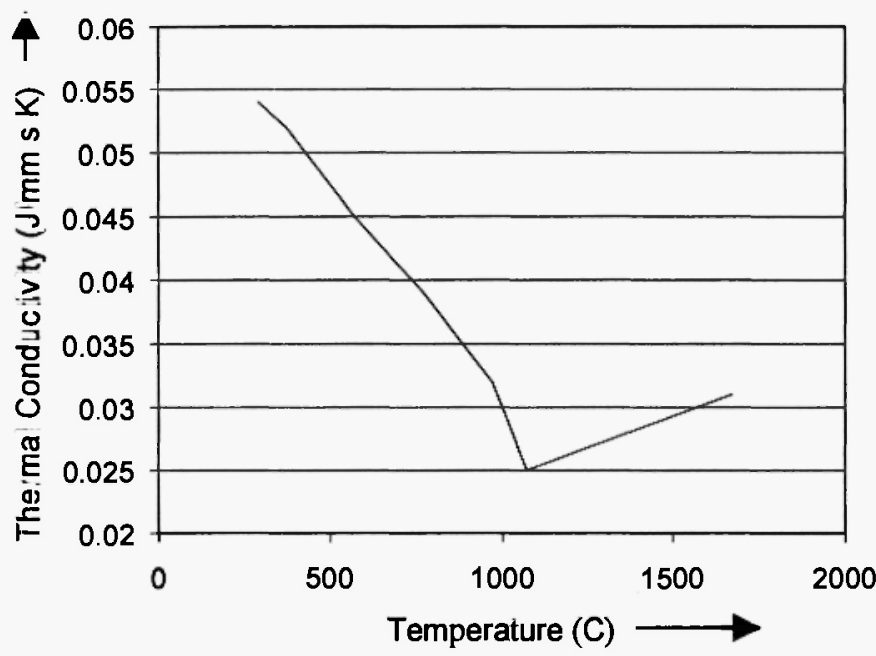

Fig. 2: Variation of thermal conductivity with temperature

\section{Heat Flow Equation}

The temperature $T(t, x, y, z)$ as a function of time and spatial coordinates $(x, y, z)$ satisfies the following diffusion equation at every point within a finite domain

$$
\frac{\partial T}{\partial t}=\nabla\left(\frac{\lambda \nabla T}{\rho c}\right)+\frac{H}{\rho c}
$$

where,

$$
\begin{array}{ll}
\mathrm{H} & =Q_{s}-Q_{l} \quad \text { during heating phase beyond liquidus temperature } \\
& =Q_{s} \quad \text { during cooling phase below solidus temperature } \\
Q_{s}(t, x, y, z) & =\text { heat input from welding arc }\left(\mathrm{J} / \mathrm{s} \mathrm{mm}^{3}\right) \\
Q_{l}(t, x, y, z) & =\text { latent heat of fusion }\left(\mathrm{J} / \mathrm{s} \mathrm{m}^{3}\right) \\
\mathrm{C} & =\text { specific heat }(\mathrm{J} / \mathrm{kg} \mathrm{K}) \\
\lambda & =\text { thermal conductivity }(\mathrm{J} / \mathrm{mm} \mathrm{s} \mathrm{K)} \\
\mathrm{T} & =\mathrm{T}(\mathrm{t}, \mathrm{x}, \mathrm{y}, \mathrm{z}) \quad(\mathrm{K}) \\
\mathrm{t} & =\operatorname{time~}(\mathrm{s}) \\
\rho & =\text { density }\left(\mathrm{kg} / \mathrm{mm}^{3}\right)
\end{array}
$$




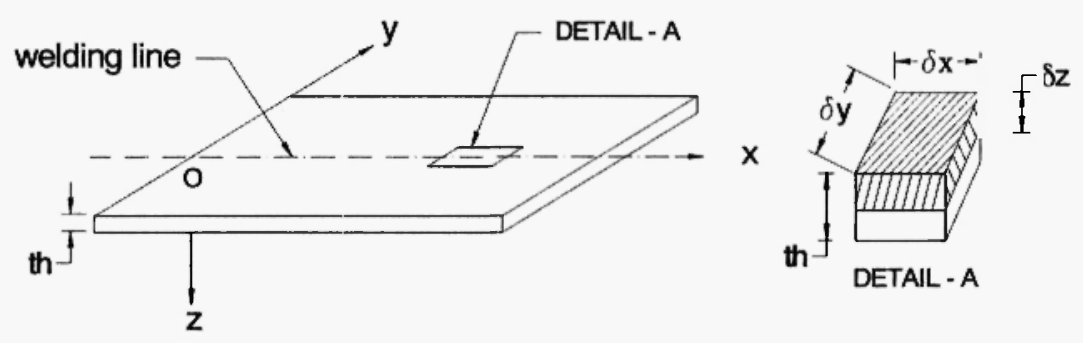

Fig. 3: Axis system and heat input model

The axis system and the heat input model are shown in Fig. 3. Welding is carried out along the $x$-axis and hence a finer grid has been taken along the $y$-axis and z-axis. After the initial transient state the temperature history is going to repeat itself, leading to a quasi-stationary state. Hence a coarse grid has been chosen along the $\mathrm{x}$-axis (Fig. 4). Considering the welding line to be on the plane of symmetry only one half of the plate has been taken as the calculation domain.

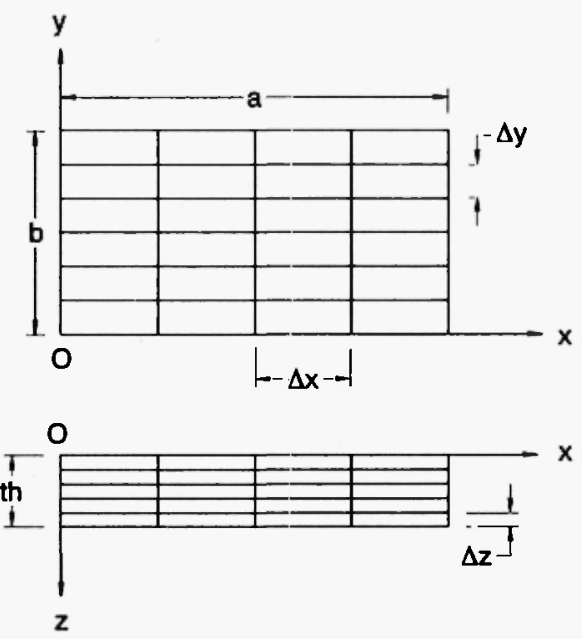

Fig. 4: Grid system and mesh dimensions

The heat loss, due to radiation, conduction through electrode and heat consumed towards burning of flux and melting of electrode, were accounted for by the arc efficiency parameter $\eta$. In the present study considering a submerged arc, welding value of 0.9 has been taken for $\eta$. Therefore, the net heat available to the plate is $\eta . V . l$, where arc voltage is $V$ and arc current is $I$. This has been considered to be uniformly distributed over the shaded part as shown in Fig. 3. Therefore, the heat input per unit volume is given by

$$
Q_{s}=\frac{\eta \cdot V \cdot I}{\delta x \cdot \delta y \cdot \delta z} \quad \mathrm{~J} / \mathrm{s} \cdot \mathrm{mm}^{3}
$$




\section{Boundary Conditions}

The calculations were performed only for half of the plate because of symmetry about $y=0$ (Fig. 4). Along the plane of symmetry the following boundary condition was defined:

$$
\begin{aligned}
& \text { at } y=0 \text { : } \\
& \qquad \frac{\partial T_{i, j, k}}{\partial y}=0 \Rightarrow T_{i,-1, k}=T_{i, !, k}
\end{aligned}
$$

Along the other three boundaries and on the top and bottom surfaces of the plate, heat dissipation will occur through convection. Therefore, the following boundary conditions were defined for various surfaces:

$$
\text { at } \begin{aligned}
x & =0: \\
& -\lambda \frac{\partial T(0, y, z)}{\bar{\partial} x}+h\left(T_{\mathrm{c}, y, z}-T_{0}\right)=0 \\
& \Rightarrow T_{-1, y, z}=T_{1, y, z}-C_{x}\left(T_{0, y, z}-T_{0}\right)
\end{aligned}
$$

where $\mathrm{h}=$ convection coefficient at plate edges.

$$
\begin{aligned}
\text { at } x & =x x \\
& \lambda \frac{\partial T_{x x, y, z}}{\bar{\partial} x}+h\left(T_{x x, y, z}-T_{0}\right)=0 \\
& \Rightarrow T_{x x+1, y, z}-T_{x x-1, y, z}-C_{x}\left(T_{x x, y, z}-T_{0}\right)
\end{aligned}
$$

where $C_{x}=\frac{2 \cdot \Delta x \cdot h}{\lambda}$

at $y=y y$ :

$$
\begin{aligned}
& \lambda \frac{\partial T_{: \because, y y, z}}{\partial y}+h\left(T_{x, y y, z}-T_{0}\right)=0 \\
& \Rightarrow T_{x, y y+1, z}=T_{x, y y-1, z}-C_{y}\left(T_{x, y y, z}-T_{0}\right)
\end{aligned}
$$

where $C_{y}=\frac{2 \cdot h \cdot \Delta y}{\lambda}$. 
at $z=0$ :

$$
\begin{gathered}
-\lambda \frac{\partial T_{x, y, 0}}{\partial z}+h_{\imath}\left(T_{x, y, 0}-T_{0}\right)=0 \\
\Rightarrow T_{x, y,-1}=T_{x, y, 1}-C_{z t}\left(T_{x, y, 0}-T_{U}\right)
\end{gathered}
$$

where $C_{z t}=\frac{\mid 2 . \Delta z \cdot h_{t}}{\lambda} . \quad \mathrm{h}_{\mathrm{t}}=$ top surface convection coefficient.

at $z=z z$ :

$$
\begin{aligned}
& \lambda \frac{\partial T_{x, y, z z}}{\partial z}+h_{b}\left(T_{x, y, z z}-T_{0}\right)=0 \\
& \Rightarrow T_{x, y, z z+1}=T_{x x, y, z z-1}-C_{z b}\left(T_{x, y, z z}-T_{\tilde{0}}\right)
\end{aligned}
$$

where $C_{z b}=\frac{\mid 2 \cdot i \Delta z \cdot h_{b}}{\lambda} . \quad h_{b}=$ bottom surface convection coefficient.

In addition to these boundary conditions, the initial condition over the entire plate was defined as,

$$
T_{0, x, y, z}=T_{0}
$$

where $T_{0}=$ ambient temperature.

\section{Solution Procedure}

The governing equations were represented in a finite difference form following a centre difference implicit scheme. The numerical solution of equation (1) with appropriate boundary conditions (3) - (9), requires fine grids along the $y$ and $z$ axis and a small time step to ensure conservation of energy during each time step. The fine grids in the 3-D problem led to a very large sparse matrix resulting in a limitation to the calculation domain size. This limitation was overcome by using the Jacobi iteration scheme to solve the system of difference equations. The coefficient matrix of this system of equations not being diagonally dominant, exhibits the problem of non-convergence. Therefore, under- relaxation has been employed in the Jacobi iteration scheme for dampening out the oscillations.

The temperature dependence of the thermo-physical properties have been incorporated by an iterative process subject to a predefined convergence criterion. The Jacobi iteration and iteration to accommodate variation of thermo-physical properties with temperature run simultaneously. The entire code has been written in VC++ environment. The model used $30 \times 50 \times 8$ grid system for $6 \mathrm{~mm}$ plate, $30 \times 50 \times 10$ for 8 $\mathrm{mm}$ plate, $30 \times 50 \times 12$ for $10 \mathrm{~mm}$ plate and $30 \times 50 \times 14$ for $12 \mathrm{~mm}$ plate, for the calculation of temperature 
history over 50 time steps. Each time step being 0.2 second. Non-uniform grid spacing was used to get better resolution.

\section{EXPERIMENTAL VALIDATION}

Samples each of $6 \mathrm{~mm}, 8 \mathrm{~mm}, 10 \mathrm{~mm}$ and $12 \mathrm{~mm}$ thickness were taken with square edge preparation. The chemical composition of the steel is given in Table 1.

Table-1

Chemical Composition of C-M $\mathrm{M}_{\mathrm{n}}$ Steel

\begin{tabular}{|c|c|c|c|c|c|c|c|c|c|}
\hline $\mathbf{C}$ & $\mathbf{S i}$ & $\mathbf{M n}$ & $\mathbf{P}$ & $\mathbf{S}$ & $\mathbf{C r}$ & $\mathbf{N i}$ & $\mathbf{M o}$ & $\mathbf{C u}$ & $\mathbf{A l}$ \\
\hline 0.19 & 0.37 & 1.57 & 0.023 & 0.027 & 0.06 & 0.03 & 0.01 & 0.04 & 0.046 \\
\hline
\end{tabular}

Single run submerged arc welding with backing strip was carried out using a $600 \mathrm{~A}$ constant voltage DC power source. The welding was carried out using direct current electrode positive with a $3.15 \mathrm{~mm}$ diameter mild steel welding wire. The contact tube to the work piece distance was kept at $30 \mathrm{~mm}$ and a root gap of 3 $\mathrm{mm}$ was kept for all samples. The welding parameters used are given in Table 2.

Table 2

Welding Parameters

\begin{tabular}{|c|c|c|c|c|}
\hline \multirow{2}{*}{ Sl. No. } & $\begin{array}{c}\text { Plate thickness } \\
(\mathbf{m m})\end{array}$ & $\begin{array}{c}\text { Current } \\
(\mathbf{A})\end{array}$ & $\begin{array}{c}\text { Voltage } \\
(\mathbf{V})\end{array}$ & $\begin{array}{c}\text { Speed } \\
(\mathrm{mm} / \mathbf{s})\end{array}$ \\
\cline { 3 - 5 } & & 480 & 24 & 12 \\
\hline 1 & 6 & 470 & 24 & 12 \\
\hline 2 & 8 & 460 & 26 & 8.5 \\
\hline 3 & 10 & 560 & 27 & 12.5 \\
\hline 4 & 12 & & & \\
\hline
\end{tabular}

After welding, each sample was cross-sectioned, polished to a $1 \mu \mathrm{m}$ finish using silicon curbide paper and etched in a $2 \%$ Nital solution. It revealed two distinct isothermal lines of solidus $\left(1495^{\circ} \mathrm{C}\right)$ and $\mathrm{A}_{1}$ transformation $\left(723^{\circ} \mathrm{C}\right)$ temperatures. The etched sections of one from each thickness groups are shown in Figs. 5 to 8 . The fusion zone width at the plate surface indicating maximum width of weld pool and fusion depth indicating depth of penetration were measured. The measured values are shown in Table 3. 


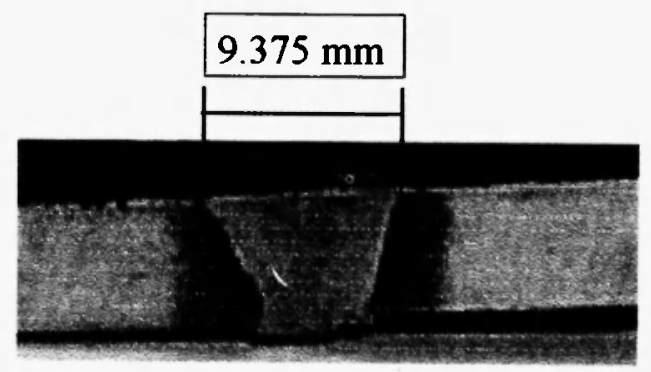

Fig. 5: Fusion zone of $6 \mathrm{~mm}$ plate square butt

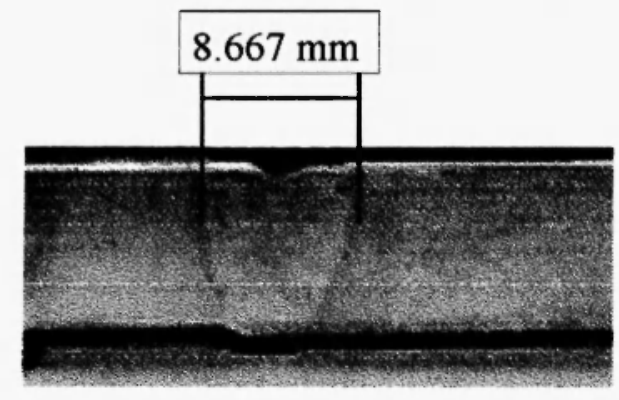

Fig. 6: Fusion zone of $8 \mathrm{~mm}$ plate square butt

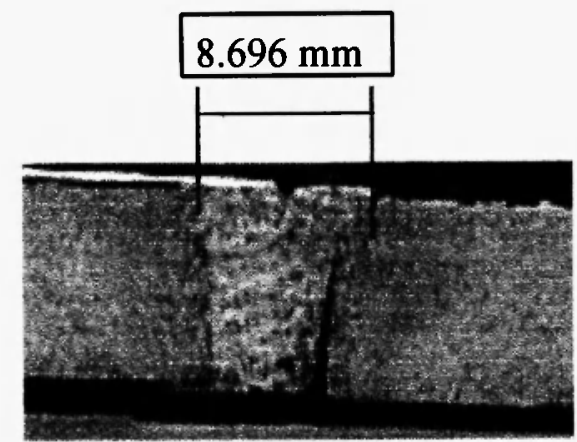

Fig. 7: Fusion zone of $10 \mathrm{~mm}$ plate square butt

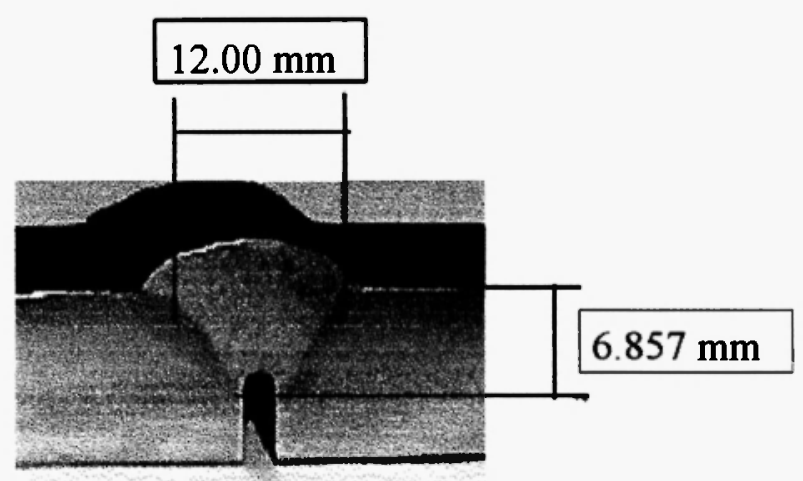

Fig. 8: Fusion zone of $12 \mathrm{~mm}$ plate square butt 
Table 3

Fusion Zone Dimensions

\begin{tabular}{|c|c|c|c|c|c|}
\hline SI. No. & Plate thickness (mm) & \multicolumn{2}{|c|}{ Measured } & \multicolumn{2}{c|}{ Calculated } \\
\hline & & $\begin{array}{r}\text { Width } \\
(\mathrm{mm})\end{array}$ & $\begin{array}{r}\text { Depth } \\
(\mathrm{mm})\end{array}$ & $\begin{array}{c}\text { Width } \\
(\mathrm{mm})\end{array}$ & $\begin{array}{c}\text { Depth } \\
(\mathrm{mm})\end{array}$ \\
\hline 1 & 9.375 & 6.00 & 9.200 & 6.00 \\
\hline 2 & 8 & 8.667 & 8.00 & 9.80 & 8.00 \\
\hline 3 & 10 & 8.696 & 10.00 & 8.40 & 10.00 \\
\hline 4 & 12 & 12.00 & 6.857 & 11.60 & 6.60 \\
\hline
\end{tabular}

\section{RESULTS}

\section{Fusion Zone Dimensions}

The three-dimensional transient temperature field for welding parameters as given in Table 2 was obtained by solving the heat flow equation for submerged arc welding of C-Mn steel. The fusion boundary indicated by the solidus temperature isotherm and HAZ boundary by $723{ }^{\circ} \mathrm{C}$ isotherm for $6 \mathrm{~mm}, 8 \mathrm{~mm}, 10 \mathrm{~mm}$ and $12 \mathrm{~mm}$ plates are shown in Fig. 9 to 12 . The surface temperature distributions at various points along the welding line are shown in Fig. 13 and 14 for $6 \mathrm{~mm}$ and $12 \mathrm{~mm}$ plates respectively.

The fusion zone dimensions were estimated from the isotherm plots and have been indicated in Table 3 . The calculated results match fairly well with the measured ones.

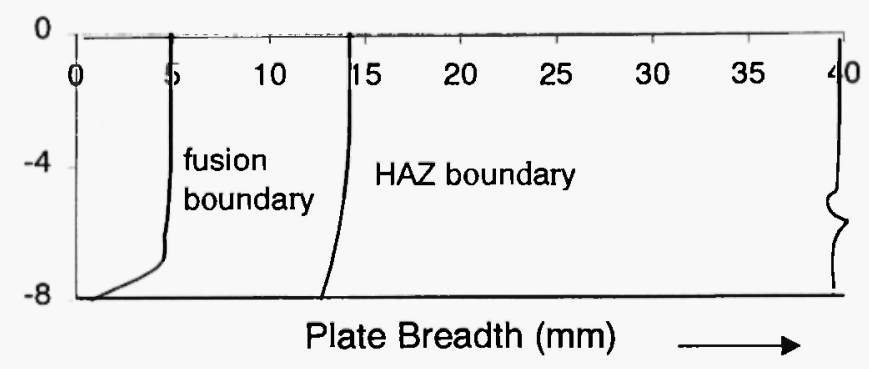

Fig. 9: Solidus temperature and $723^{\circ} \mathrm{C}$ temperature isotherm for $6 \mathrm{~mm}$ plate 


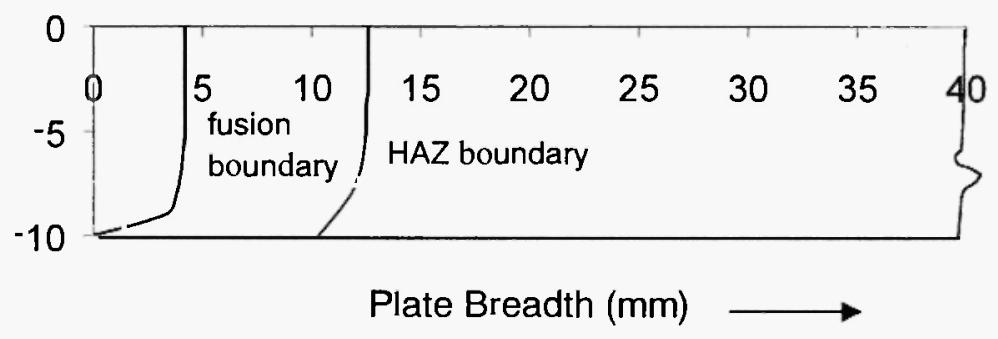

Fig. 10: Solidus temperature and $723^{\circ} \mathrm{C}$ temperature isotherm for $8 \mathrm{~mm}$ plate

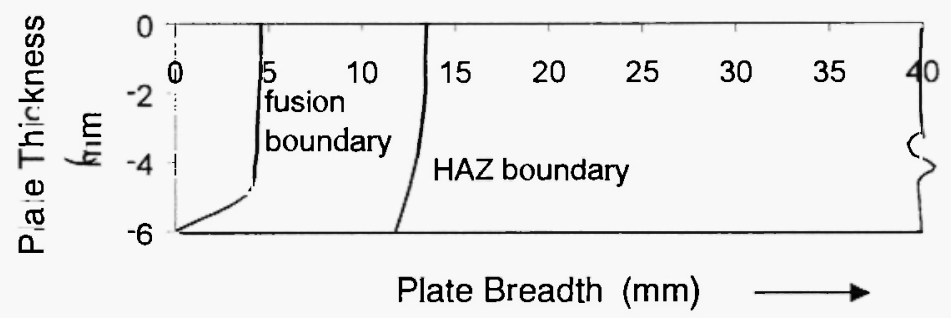

Fig. 11: Solidus temperature and $723^{\circ} \mathrm{C}$ temperature isotherm for $10 \mathrm{~mm}$ plate

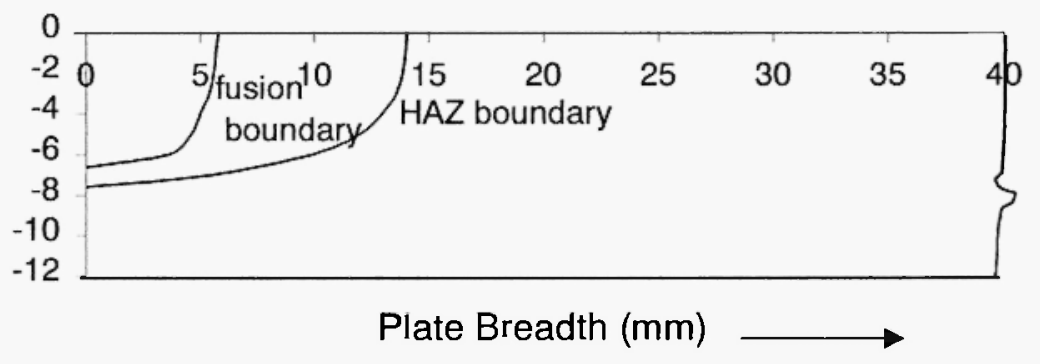

Fig. 12: Solidus temperature and $723^{\circ} \mathrm{C}$ temperature isotherm for $12 \mathrm{~mm}$ plate

\section{HAZ and Cooling Rates}

The temperature contour plots corresponding to the solidus temperature of $1495^{\circ} \mathrm{C}$ and $\mathrm{A}_{1}$ transformation temperature of $723^{\circ} \mathrm{C}$ are shown in Figs. 9 to 12 . The zone between these two curves represents the HAZ.

Cooling time $t_{\mathrm{s} /, 5}$ between $800^{\circ} \mathrm{C}$ and $500^{\circ} \mathrm{C}$ is often used to assess transformation phenomena of ferritic steels. Cooling time up to $100^{\circ} \mathrm{C}, \mathrm{t}_{100}$, is an important parameter for assessing possibility of hydrogen embrittlement. These cooling rates at $x=72 \mathrm{~mm}$ and $\mathrm{x}=24 \mathrm{~mm}$ for $6 \mathrm{~mm}$ and $12 \mathrm{~mm}$ plates are shown in Figs. 13 and 14 respectively. $t_{8 / 5}$ at $x=72 \mathrm{~mm}$ for $6 \mathrm{~mm}$ plate is $9.0 \mathrm{~s}$ and that for $12 \mathrm{~mm}$ plate is $3.4 \mathrm{~s}$. The cooling rate is somewhat faster for the thinner plate at the initial stages of welding as can be seen in Fig. 14. The $t_{8 / 5}$ 


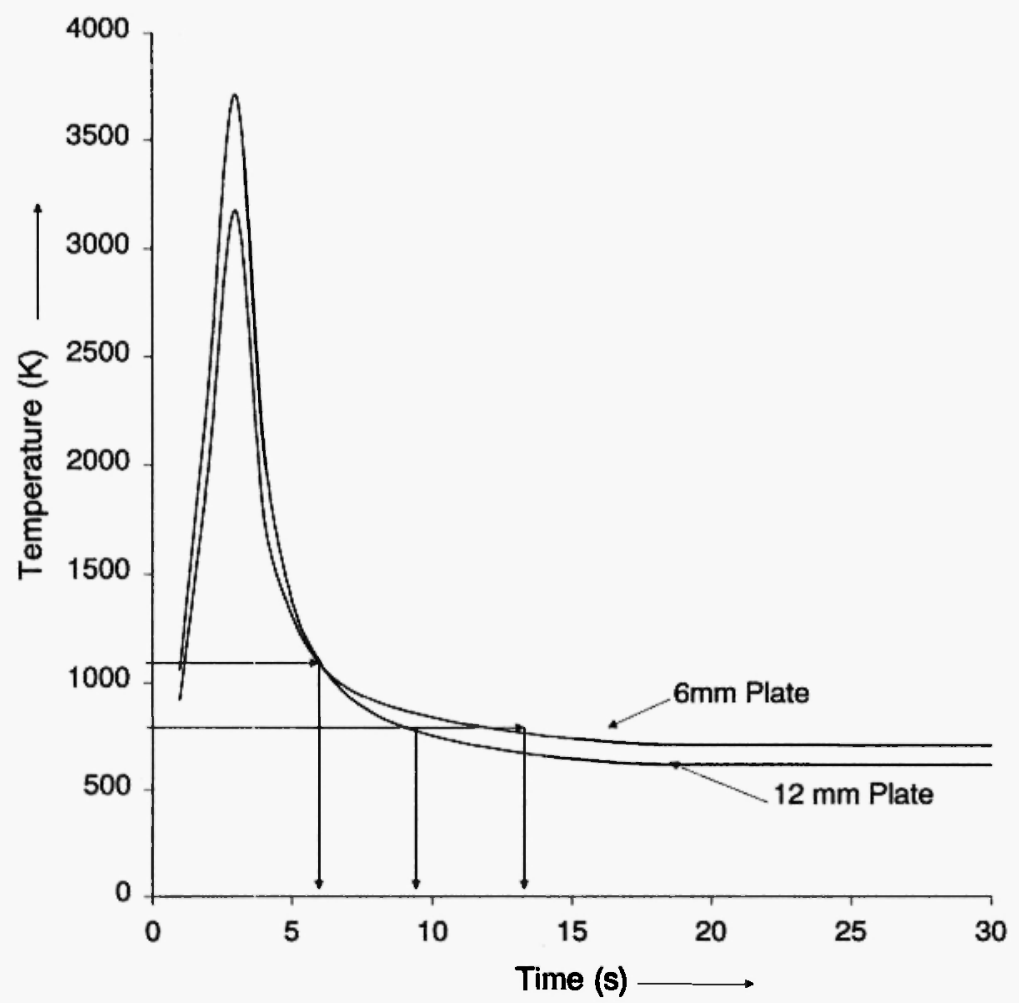

Fig. 13: Surface temperature distribution at $\mathrm{x}=72 \mathrm{~mm}$ showing the cooling times from $800{ }^{\circ} \mathrm{C}$ to $500{ }^{\circ} \mathrm{C}$ for $6 \mathrm{~mm}$ plate $9.0 \mathrm{~s}$ and for $12 \mathrm{~mm}$ plate $3.4 \mathrm{~s}$.

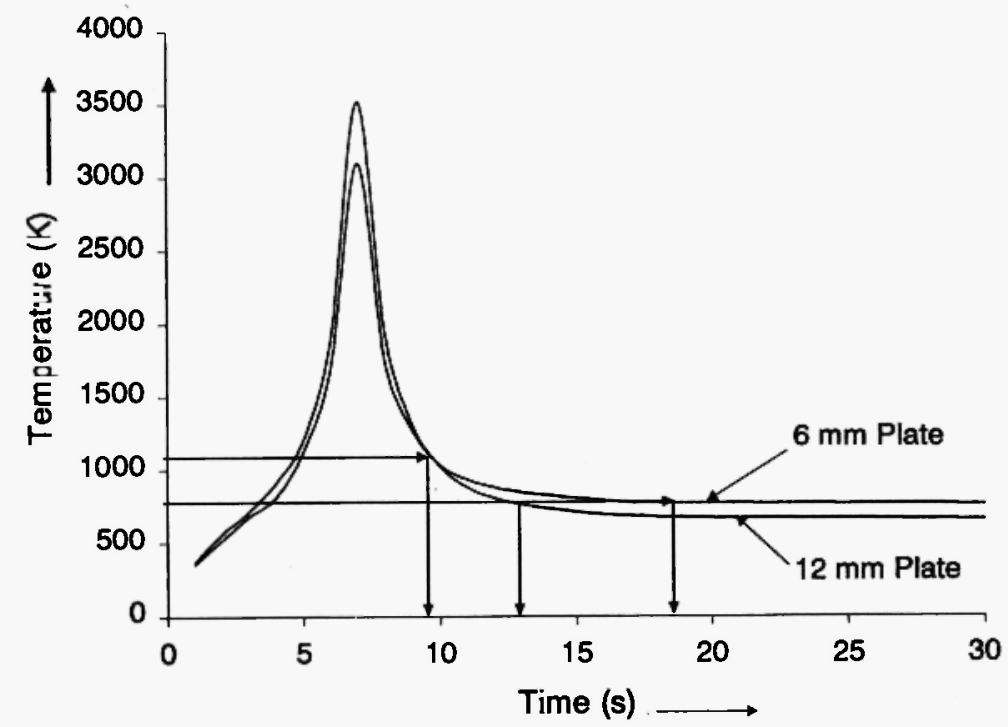

Fig. 14: Surface temperature distribution at $\mathrm{x}=24 \mathrm{~mm}$ showing the cooling times from $800{ }^{\circ} \mathrm{C}$ to $500{ }^{\circ} \mathrm{C}$ for $6 \mathrm{~mm}$ plate $7.3 \mathrm{~s}$ and for $12 \mathrm{~mm}$ plate $3.5 \mathrm{~s}$. 
cooling times for the position $\mathrm{x}=24 \mathrm{~mm}$ for $6 \mathrm{~mm}$ plate is $7.3 \mathrm{~s}$ and that for $12 \mathrm{~mm}$ plate is $3.5 \mathrm{~s}$. For the thicker plate, cooling time stabilises faster as compared to thinner plate. With increase in plate thickness one can observe higher cooling rates as shown in Figs. 13 and 14.

\section{CONCLUSIONS}

1) An implicit centre difference scheme with a simplified heat source model has been implemented to simulate the transient 3-D thermal cycle. It closely approximates the actual welding conditions.

2) The transient temperature distribution was obtained with convection boundary conditions on all the three plate boundaries and top and bottom surfaces. The latent heat of fusion and temperature dependent thermo-physical properties have been taken into account.

3) The numerical results for the fusion zone dimensions compared fairly well with those of experiments. It indicates a promise for predicting weld metal and $\mathrm{HAZ}$ microstructure as well as distortion and residual stress.

4) Increase in plate thickness indicated increase in cooling rate, thereby increasing the possibility of hydrogen embrittlement.

5) For thicker plate cooling rate stabilises faster as compared to thinner plate.

6) The parameters defining the heat source model, presented in this work, can be easily estimated unlike in the case of Gaussian heat source models.

\section{REFERENCES}

1. D. Rosenthal. Mathematical theory of heat distribution during welding and cutting. Welding Journal, 21(5), 220-s to 234-s (1941).

2. D. Rosenthal. The theory of moving sources of heat and its application to metal treatments. Trans. AlME, 43(11), 849-866 (1946).

3. S. Tanaka. A study on heat conduction of a moving heat source. Journal Japan Welding Society, 13(9), 347-359 (1943).

4. A. Wells. Heat flow in welding. Welding Journal, 31(5), 263-s to 267-s (1952).

5. C.M. Adams, Jr. Cooling rates and peak temperatures in fusion welding. Welding Journal, 35(5), 210-s to 215 -s (1958).

6. N. Christensen, V. Davis and K. Gjermundsen. Distribution of temperatures in arc welding. British Welding Journal, 12(2), 54-75 (1965).

7. T. Eagar and N. Tsai. Temperature field produced by traveling distributed heat sources. Welding Journal, 62(12), 346-s to 355-s (1983).

8. A.C. Nunes, Jr. An extended Rosenthal weld model. Welding Journal, 62(6), 165-s to 170-s (1983). 
9. N.H. Rykalin and A.I. Beketov. Calculating the thermal cycle in the heat -affected zone from the twodimensional outline of the molten pool. Welding Production, 14(9), 42-47 (1967).

10. T. Kasuya and N. Yurioka. Analysis of three-dimensional heat conduction in welding by dispersed point heat sources. $I I W$. Doc. $I X, 1554-89$ (1989).

11. T. Terasaki, T. Akiyama, K. Ishimoto and Y. Mori. Proposal of equations to estimate the cooling time $\mathrm{t}_{8 / 5}$, from $800^{\circ} \mathrm{C}$ to $500^{\circ} \mathrm{C}$. Quarterly Journal Japan Welding Society, 6(2), 301-305 (1988).

12. T. Kasuya and N. Yurioka. Prediction of welding thermal history by a comprehensive solution. Welding Journal, 107-s to 115-s (Mar.1993).

13. K. Mundra et al. Weld metal microstructure calculations from fundamentals of transport phenomena in the arc welding of low-alloy steels. Welding Journal, 163-s to 171-s (Apr. 1997).

14. S. Ohring and H.J. Lugt. Numerical simulation of a time-dependent 3-D GMA weld pool due to a moving arc. Welding Journal, 79(12), 416-s to 424-s (1999).

15. J. Goldak et al. A new finite element model for welding heat source. Metallurgical Transactions $B$, 15B, 299-305 (1984).

16. N.R. Mandal and Santha Ram Akella. A finite difference model for prediction of welding thermal history. Journal of the Mechanical Behaviour of Materials, 11(5), 381-392 (2000).

17. $\varnothing$. Gundersen et al. Modelling of residual stresses in weld simulated restrained C-Mn steel specimen. Proceedings of Ninth (1999) International Offshore and Polar Engineering Conference, Brest, France, May 30 - June 04, 187-194 (1999). 